\title{
Inflammation, iron and vitamin D metabolism in different cardiomyopathy aetiologies
}

https://doi.org/10.1515/pteridines-2020-0004

received June 25, 2019; accepted February 19, 2020.

Abstract: Immune activation coincides with disturbances in iron and vitamin $\mathrm{D}$ metabolism in patients with cardiomyopathy. In this study, we investigated whether there are differences regarding immune activation, iron and vitamin D metabolism between the different cardiomyopathy aetiologies.

Patients and methods: Parameters of iron metabolism (haemoglobin, iron, transferrin, transferrin saturation, ferritin, hepcidin), vitamin D metabolism (Ct-FGF23, parathormone, phosphate, vitamin D) and immune activation (C-reactive protein and neopterin) were determined in 149 patients (98 men, 51 women) with non-ischaemic cardiomyopathy.

Results: Patients with amyloid cardiomyopathy presented with higher neopterin, ferritin and hepcidin levels than other cardiomyopathy aetiologies. Furthermore, they showed the highest rate of cardiovascular events. C-reactive protein levels were significantly higher in patients with inflammatory cardiomyopathy. Patients with virus positive cardiomyopathy presented with significantly higher ferritin and Ct-FGF23 levels compared to patients with virus negative inflammatory cardiomyopathy.

Conclusion: This study indicates that there are some differences regarding the extent of immune activation and inflammation as well as alterations in iron metabolism disorders between different cardiomyopathy aetiologies. Further studies with larger patient cohorts are needed to investigate these findings more precisely.

\footnotetext{
*Corresponding author: Katharina Kurz, Department of Internal Medicine II, Medical University of Innsbruck, 6020 Innsbruck, Austria, E-mail: Katharina.Kurz@i-med.ac.at Lukas Lanser, Nada Nemati, Markus Seifert, Günter Weiss, Department of Internal Medicine II, Medical University of Innsbruck, 6020 Innsbruck, Austria

Dietmar Fuchs, Division of Biological Chemistry, Biocenter, Medical University of Innsbruck, 6020 Innsbruck, Austria

Gerhard Pölzl, Department of Internal Medicine III, Medical University of Innsbruck, 6020 Innsbruck, Austria
}

Keywords: cardiomyopathy; immune activation; anaemia; iron deficiency; FGF23.

\section{Introduction}

Cardiomyopathies (CMPs) represent a heterogenic group of heart muscle disease. The heart muscle can be affected as a primary pathologic process or secondarily in the course of a systemic disorder. CMPs can be classified due to their morphology into dilated CMP (DCM), hypertrophic CMP (HCM), restrictive CMP (RCM), arrhythmogenic right ventricular CMP (ARVC) and undefined CMP [1-3]. DCM is the most common morphologic form of CMP with rising incidence and defined as dilatation of the left ventricle (LV) and later on of both ventricles [4]. HCM is the most common genetic heart disease and the most common cause of sudden cardiac death in young adults [5]. Its morphology is characterised by a cardiac hypertrophy especially of the LV [6]. RCM is the most uncommon morphologic form of CMPs in developed countries and characterised by an increased myocardial stiffness reflected by diastolic dysfunction usually of the LV [7]. ARVC is a relatively uncommon genetic heart disease that typically affects men between the second and fourth decade of life and is associated with loss of right ventricular myocardium with following substitution by fibrous and fatty tissue [8].

CMPs can also be classified due to the underlying aetiology. A widely used classification by the World Health Organisation (WHO) divides CMPs into inflammatory, ischaemic, hypertensive, valvular, metabolic, toxic, peripartum and tachycardic CMP [1] and can be completed with genetic and idiopathic aetiology. Inflammatory CMP, also described as myocarditis, presents as DCM and can be infective-induced or noninfective-induced [9-11]. A wide variety of infectious agents including viral (e.g. human herpesvirus 6, parvovirus B19, coxsackievirus $\mathrm{A} / \mathrm{B}$, adenovirus) $[10,12]$, bacterial (e.g. meningococcus, 
borreliosis, diphtheria) [13], rickettsial (e.g. typhus) [14], fungal (e.g. aspergillosis, candiasis) $[9,15]$ and parasitic pathogens (Chagas diseases, toxoplasmosis) [16, 17] can cause an inflammatory process in the myocardium. On the other hand, myocarditis can occur in course of a hypersensitivity reaction to drugs (e.g. antibiotics, sulphonamides, anticonvulsants, anti-inflammatories) [18-22] or a radiotherapy of the mediastinum [9] or as an autoimmunologic process in the course of a rheumatoid arthritis, collagenosis or vasculitis [9, 23, 24]. Metabolic CMP can be caused by endocrine diseases (e.g. diabetes mellitus, storage disease (e.g. lysosomal storage disease, glycogen storage disease, haemochromatosis), nutritional related deficiency diseases (vitamin $\mathrm{B}_{1}$ deficiency), neuromuscular diseases (e.g. neurofibromatosis) or amyloidosis [25].

We know that immune activation plays an important role in different CMP aetiologies (e.g. inflammatory, metabolic or toxic CMP) [26]. Immune activation is also related to alterations of iron metabolism [27]. Actually, both iron deficiency and iron overload affect the CMP pathophysiology [28]. Iron deficiency reduces exercise tolerance [29] and leads to progressive heart failure and increased mortality [30], while iron overload and consequently increased oxidative stress induces CMP [31]. Finally, the recently detected FGF23 also effects the heart function [32] and interacts with the immune system and iron metabolism [33]. Since immune activation as well as alterations in iron and vitamin D metabolism effect heart function, we were interested, whether these mechanisms differ between patients with different CMP morphologies and aetiologies.

\section{Methods}

\section{Study population}

Within this retrospective study, we analysed a data set that initially included 475 Caucasian patients with heart failure (HF) due to nonischaemic cardiomyopathy (CMP), who underwent right heart catheterization between 2009 and 2014 in the Cardiology department of the Innsbruck University Hospital. We only included data of 149 patients (98 men, 53 women) for further statistical analyses, since data regarding biomarkers of immune activation and inflammation (CRP, neopterin), iron metabolism parameters (haemoglobin, iron, ferritin, transferrin, transferrin saturation) and vitamin D metabolism parameters (including C-terminal fibroblast growth factor
23 (Ct-FGF23) concentrations) were not available for all patients. Acute HF, coronary artery disease on coronary angiography or vitamin $\mathrm{D}$ or calcium supplement within the last 6 months were also exclusion criteria. The diagnosis of HF was made due to the presence of current or previous symptoms or characteristic clinical signs and evidence of LV dysfunction. Patients were treated according to CHF guidelines.

Ethical approval: The research related to human use has been complied with all the relevant national regulations, institutional policies and in accordance with tenets of the Helsinki Declaration, and has been approved by the local ethics committee of Innsbruck Medical University (ID of the Ethical votum: UN4280, session number 298/4.11).

Informed consent: Informed consent has been obtained from all individuals included in this study

\section{Follow-up analysis}

Theevent-free survival was defined as period of time between the first hospitalisation and the combined endpoint, which was either a heart transplantation (HTx), a ventricular assist device (VAD) implantation, a re-hospitalisation for cardiac decompensation or patients' death. Cut-off date for the follow-up was May 2017. Information about those events were received from the clinical information system (KIS), the local mortality registry, from the patients' relatives or from the patients themselves.

\section{Measurements}

Fasting blood samples were drawn in all patients at study entry and stored at $-80^{\circ} \mathrm{C}$. All routine laboratory variables were measured at our central laboratory that undergoes regular internal and external quality audits. Neopterin was measured by an enzyme-linked immunosorbent assay (ELISA; IBL International $\mathrm{GmbH}$, Hamburg, Germany) and the C-reactive protein (CRP) by an immunoturbidimetry test (Roche, Mannheim, Germany). Creatinine and NT-proBNP were determined by standardized automated tests. Hepcidin-25 levels were determined by ELISA (DRG Instruments GmbH, Marburg, Germany) in 91 patients. Iron levels were measured with the FerroZine ${ }^{\mathrm{TM}}$ method without deproteinization (Merck KGaA, Darmstadt, Germany). Ferritin levels were detected with an immunoturbidimetry test containing anti-ferritin antibodies from rabbits (Roche, Mannheim, Germany). Transferrin levels were also detected with an 
immunoturbidimetry test containing specific antibodies from rabbits (Roche, Mannheim, Germany). The transferrin saturation (TSAT) was calculated as followed: iron / transferrin $x$ 70.9. Haemoglobin levels were analysed photometrically at $555 \mathrm{~nm}$ (XE-5000, Sysmex GmbH, Wien, Austria). FGF23 was determined using an FGF23 assay (Immutopics Inc., San Clemente, CA, USA; interassay coefficient of variation $<5 \%$ ) that detects epitopes within the carboxyl-terminal domain of FGF23 (Ct-FGF23) with polyclonal antibodies. Therefore, the test used in this study detects both cFGF23 and iFGF23. Circulating concentrations of Ct-FGF23 are expressed as relative units per millilitre $(\mathrm{RU} / \mathrm{mL})$. Glomerular filtration rate (GFR) was estimated using the IDMS-traceable MDRD Study equation (estimated glomerular filtration rate [eGFR] [mL/ $\min / 1.73 \mathrm{~m}^{2}$ ] $=175 \mathrm{x}$ [serum creatinine] $-1.154 \mathrm{x}$ age -0.203 [x 0.742 if female]).

The cardiac output (CO) was measured in course of a left heart catheterisation and the left ventricular ejection fraction (LV-EF) was measured by echocardiography.

\section{Statistical analysis}

Data are presented as median $\left(25^{\text {th }}, 75^{\text {th }}\right.$ percentile) or $n$ (\%), as appropriate. Shapiro-Wilks test was used to test for normality in distribution of included parameters. Nonnormally distributed parameters are expressed as median with interquartile range (IQR) and were compared by non-parametric tests (Mann-Whitney U, Kruskal-Wallis). Outcome differences between classified subgroups were analysed with the Log-rank test.

P-values $<0.05$ were considered to indicate statistical significance. Statistical analysis was performed using SPSS 24.0 for Macintosh (IBM Corp., Armonk, NY, USA).

\section{Results}

\section{Patient characteristics: NYHA classification}

When classifying the patients by the New York Heart Association (NYHA) functional classification, 33 patients (22.3 \%) had NYHA class 1, 65 patients (44.2\%) had NYHA class 11,36 patients (24.5\%) had NYHA class 111 and 13 patients ( $8.8 \%$ ) had NYHA class IV. Patients were further classified according to the functional (morphological) CMP classification by the European Society of Cardiology (ESC, 2008) [2]: 94 patients (63.1\%) had a dilative cardiomyopathy (DCM), 26 patients (17.4 \%) had a hypertrophic cardiomyopathy (HCM), 13 patients $(8.7 \%)$ had a restrictive cardiomyopathy (RCM) and 16 patients $(10.7 \%)$ had an undefined CMP. Demographic and epidemiologic data, laboratory measurements and haemodynamics within the morphologic subgroups are listed in Table 1.

Patients with RCM had a preserved LV-EF over 50\%, were older and tended to have the highest NT-proBNP levels. Patients with DCM had the lowest LV-EF, and a higher cardiac output (CO) compared to patients with RCM. The highest neopterin concentrations were found in patients with RCM, while those patients had the lowest CRP concentrations. (Table 1)

\section{Patient characteristics: CMP aetiology classification}

Patients were also classified due to the basic CMP aetiology: 31 patients $(20.8 \%)$ were described to have an idiopathic, 8 patients ( $5.4 \%$ ) to have a genetic, 4 patients ( $2.7 \%)$ to have a hypertensive, 85 patients $(57.0 \%)$ to have an inflammatory, 4 patients (2.7 \%) to have a toxic and 17 patients $(11.4 \%)$ to have a metabolic aetiology. Patients with metabolic aetiology were exclusively patients with amyloidosis.

We also divided the inflammatory aetiology into virus negative ( $n=69,81.2 \%)$, virus positive $(n=10,11.8 \%)$ and postinflammatory $(n=6,7.1 \%)$.

Patients with inflammatory CMP had a significantly lower LV-EF compared to patients with no inflammatory CMP (29.7 \% [23.8 - 44.5] vs. $43.8 \%$ [29.0 - 56.0], $p=$ 0.001). Patients with amyloid CMP had a significantly higher LV-EF compared to patients with no amyloid CMP $(57.2 \%$ [52.5 - 63.8] vs. $33.5 \%$ [25.0 - 45.0], $p<0.001)$ as well as higher NT-proBNP levels (2947 ng/L [1191 - 4644] vs. $1185 \mathrm{ng} / \mathrm{L}$ [455 - 3137], $p=0.013$ ).

Demographic and epidemiologic data, laboratory measurements and haemodynamics within the aetiological subgroups are listed in Table 2.

Patients with amyloid CMP had significantly higher neopterin levels ( $9.70 \mathrm{nmol} / \mathrm{L}[6.00$ - 15.30] vs. $6.80 \mathrm{nmol} / \mathrm{L}$ [4.95 - 9.15], $p=0.040$ ), but significantly lower CRP levels $(0.11 \mathrm{mg} / \mathrm{L}[0.07-0.15]$ vs. $0.24 \mathrm{mg} / \mathrm{L}$ [0.11 - 0.65], $p=$ 0.016) compared to patients with no amyloid CMP.

On the other hand CRP levels were higher in patients with inflammatory CMP compared to patients with no inflammatory CMP $(0.28 \mathrm{mg} / \mathrm{L}$ [0.12 - 0.65] vs. $0.15 \mathrm{mg} / \mathrm{L}$ [0.09 - 0.44], $p=0.050$ ), while neopterin levels showed no significant differences. 
Table 1: Laboratory measurements according to the CMP morphological classification.

\begin{tabular}{|c|c|c|c|c|c|}
\hline & undefined & RCM & DCM & HCM & Sig. \\
\hline & $\mathrm{n}=16$ & $\mathrm{n}=13$ & $\mathrm{n}=94$ & $\mathrm{n}=\mathbf{2 6}$ & \\
\hline & Median (IQR) & Median (IQR) & Median (IQR) & Median (IQR) & p-Value \\
\hline \multicolumn{6}{|l|}{ Demographic and epidemiologic data } \\
\hline Age & $36.1(30.2-53.7)$ & $70.7(56.5-73.6)$ & $46.7(38.4-54.8)$ & $59.9(45.1-66.7)$ & $<0.001$ \\
\hline BMI $\left[\mathrm{kg} / \mathrm{m}^{2}\right]$ & $24.2(19.7-32.6)$ & $23.0(21.2-25.7)$ & $24.7(22.1-27.5)$ & $25.7(23.0-28.1)$ & 0.592 \\
\hline Sex, male [\%] & 56.3 & 61.5 & 70.2 & 57.7 & 0.511 \\
\hline Hypertension [\%] & 46.7 & 69.2 & 40.2 & 50.0 & 0.243 \\
\hline Atrial fibrillation [\%] & 21.4 & 8.3 & 6.5 & 15.4 & 0.232 \\
\hline \multicolumn{6}{|l|}{ Medication } \\
\hline ACE inhibitor/ARB [\%] & 73.3 & 53.8 & 84.0 & 69.2 & 0.054 \\
\hline Beta-blocker [\%] & 53.3 & 38.5 & 86.2 & 61.5 & $<0.001$ \\
\hline MRA [\%] & 6.7 & 15.4 & 44.7 & 23.1 & 0.005 \\
\hline Diuretics [\%] & 20.0 & 61.5 & 63.8 & 53.8 & 0.012 \\
\hline Cardiac glycosides [\%] & 6.7 & 0.0 & 2.1 & 0.0 & 0.490 \\
\hline \multicolumn{6}{|l|}{ Laboratory measurements } \\
\hline $\begin{array}{l}\text { CRP }[\mathrm{mg} / \mathrm{L}] \\
\text { (Ref. } \leq 0.5)\end{array}$ & $0.42(0.25-0.78)$ & $0.12(0.07-0.15)$ & $0.21(0.10-0.64)$ & $0.19(0.11-0.57)$ & 0.070 \\
\hline $\begin{array}{l}\text { Neopterin }[\mathrm{nmol} / \mathrm{L}] \\
\text { (Ref. } \leq 8.7)[34]\end{array}$ & $6.30(4.40-9.45)$ & $9.10(5.90-10.80)$ & $6.85(4.90-9.50)$ & $7.00(5.70-10.40)$ & 0.497 \\
\hline Hepcidin [ng/mL] & $19.3(14.5-28.5)$ & $20.3(7.4-25.4)$ & $17.6(8.3-28.9)$ & $8.7(3.6-36.4)$ & 0.936 \\
\hline Iron [ $\mu \mathrm{mol} / \mathrm{L}] \quad$ (Ref. $5.8-34.5)$ & $20.0(15.3-23.7)$ & $12.2(9.2-17.9)$ & $13.8(8.7-20.3)$ & $13.6(9.7-18.6)$ & 0.053 \\
\hline Ferritin [ $\mu \mathrm{g} / \mathrm{L}] \quad$ (Ref. $30-400)$ & $92(61-224)$ & $185(71-231)$ & $156(79-265)$ & $137(57-320)$ & 0.753 \\
\hline $\begin{array}{l}\text { Transferrin [mg/dL] (Ref. } 200 \text { - } \\
\text { 360) }\end{array}$ & $259(234-279)$ & $277(233-296)$ & $271(241-299)$ & $240(207-274)$ & 0.083 \\
\hline TSAT [\%]（Ref. 16 - 45） & $32.0(24.0-36.0)$ & $17.0(13.0-35.0)$ & $21.0(13.0-30.0)$ & $23.0(16.0-30.0)$ & 0.022 \\
\hline $\begin{array}{l}\text { Haemoglobin }[\mathrm{g} / \mathrm{dL}] \\
\left.15.7^{\star} ; 13.0-17.7^{\#}\right)\end{array}$ & $13.8(12.6-14.6)$ & $13.9(13.1-14.8)$ & $14.7(13.8-15.6)$ & $14.1(12.6-14.9)$ & 0.017 \\
\hline Ct-FGF23 [RU/mL] & $16.5(9.3-33.0)$ & $37.1(20.8-49.2)$ & $22.8(14.1-46.2)$ & $24.7(15.3-53.2)$ & 0.386 \\
\hline eGFR $\left[\mathrm{mL} / \mathrm{min} / 1.73 \mathrm{~m}^{2}\right] \quad($ Ref. $>60)$ & $89.7(76.2-116)$ & $66.2(61.1-72.7)$ & $77.1(64.0-90.8)$ & $69.4(49.0-74.4)$ & 0.003 \\
\hline NT-proBNP [ng/L] (Ref. 0 - 287) & $406(191-3076)$ & $2714(1331-4664)$ & $1556(558-2979)$ & $904(501-3278)$ & 0.066 \\
\hline \multicolumn{6}{|l|}{ Haemodynamics } \\
\hline LV-EF [\%] & $41.9(34.0-50.4)$ & $56.0(55.0-63.0)$ & $28.0(23.0-41.0)$ & $54.0(43.0-62.5)$ & $<0.001$ \\
\hline $\mathrm{RAP}[\mathrm{mmHg}]$ & $9(6-11)$ & $11(8-16)$ & $9(6-12)$ & $8(6-10)$ & 0.255 \\
\hline $\mathrm{CO}[\mathrm{L} / \mathrm{min}]$ & $4.9(4.0-6.4)$ & $3.4(3.1-3.6)$ & $3.7(3.0-4.7)$ & $3.6(2.7-4.7)$ & 0.017 \\
\hline
\end{tabular}

Data from 149 patients are presented as median.

*women; "men;

$\mathrm{RCM}$ = restrictive cardiomyopathy; $\mathrm{DCM}=$ dilative cardiomyopathy; $\mathrm{HCM}=$ hypertrophic cardiomyopathy; Sig. = significance; IQR = interquartile range $\left(25^{\text {th }}\right.$ and $75^{\text {th }}$ percentile); $C M P=$ cardiomyopathy; Ref. = reference area; $A C E=$ angiotensin converting enzyme; $A R B$ $=$ angiotensin receptor blocker; $\mathrm{MRA}=$ mineralocorticoid receptor antagonist; $\mathrm{CRP}=\mathrm{C}$-reactive protein; $\mathrm{TSAT}=$ transferrin saturation; Ct-FGF23 = C-terminal fibroblast growth factor 23; eGFR = estimated glomerular filtration rate; NT-proBNP = N-terminal prohormone of brain natriuretic peptide; $\mathrm{LV}-\mathrm{EF}=$ left ventricular ejection fraction; $\mathrm{RAP}=$ right atrial pressure; $\mathrm{CO}=$ cardiac output 
Table 2: Laboratory measurements according to the CMP aetiology classification.

\begin{tabular}{|c|c|c|c|c|c|c|c|}
\hline & idiopath. & genetic & hypert. & inflam. & toxic & metabolic & Sig. \\
\hline & $\mathrm{n}=\mathbf{3 1}$ & $\mathrm{n}=\mathbf{8}$ & $\mathrm{n}=4$ & $\mathrm{n}=85$ & $\mathrm{n}=4$ & $\mathrm{n}=17$ & \\
\hline & Median (IQR) & Median (IQR) & Median (IQR) & Median (IQR) & Median (IQR) & Median (IQR) & p-Value \\
\hline \multicolumn{8}{|c|}{ Demographic and epidemiologic data } \\
\hline Age & $\begin{array}{l}47.4(35.3- \\
63.5)\end{array}$ & $\begin{array}{l}48.5(36.9- \\
57.9)\end{array}$ & $\begin{array}{l}54.6(53.4- \\
56.2)\end{array}$ & $\begin{array}{l}47.5(35.8- \\
55.5)\end{array}$ & $\begin{array}{l}35.1(29.0- \\
43.9)\end{array}$ & $\begin{array}{l}69.2(64.7- \\
73.6)\end{array}$ & $<0.001$ \\
\hline $\mathrm{BMI}\left[\mathrm{kg} / \mathrm{m}^{2}\right]$ & $\begin{array}{l}24.5(22.0- \\
27.4)\end{array}$ & $\begin{array}{l}25.4(23.2- \\
29.8)\end{array}$ & $\begin{array}{l}29.8(25.8- \\
34.8)\end{array}$ & $\begin{array}{l}24.8(21.8- \\
28.1)\end{array}$ & $\begin{array}{l}22.5(21.1- \\
24.9)\end{array}$ & $\begin{array}{l}24.9(22.0- \\
26.1)\end{array}$ & 0.334 \\
\hline Sex, male [\%] & 64.5 & 75.0 & 75.0 & 63.5 & 100.0 & 64.7 & 0.740 \\
\hline Hypertension [\%] & 38.7 & 87.5 & 100.0 & 40.2 & 0.0 & 58.8 & 0.181 \\
\hline Atrial fibrillation [\%] & 0.0 & 25.0 & 25.0 & 12.0 & 0.0 & 6.3 & 0.006 \\
\hline \multicolumn{8}{|l|}{ Medication } \\
\hline ACE inhibitor/ARB [\%] & 77.4 & 100.0 & 75.0 & 79.8 & 100.0 & 52.9 & 0.087 \\
\hline Beta-blocker [\%] & 74.2 & 62.5 & 50.0 & 83.3 & 75.0 & 41.2 & 0.005 \\
\hline MRA [\%] & 25.8 & 25.0 & 50.0 & 40.5 & 50.0 & 17.6 & 0.343 \\
\hline Diuretics [\%] & 54.8 & 50.0 & 75.0 & 58.3 & 50.0 & 58.8 & 0.795 \\
\hline Cardiac glycosides [\%] & 0.0 & 0.0 & 0.0 & 3.6 & 0.0 & 0.0 & 0.804 \\
\hline
\end{tabular}

Laboratory measurements

CRP $[\mathrm{mg} / \mathrm{L}] \quad$ (Ref. $\leq \quad 0.23(0.10-0.70) 0.11(0.07-0.83) \quad 0.31(0.11-0.86) \quad 0.28(0.12-0.65) 0.17(0.15-0.33) 0.11(0.07-0.15) 0.188$ 0.5)

Neopterin $[\mathrm{nmol} / \mathrm{L}] \quad 6.10(4.80-8.80) 6.65(4.75-11.95) 11.50(8.95-11.90) 6.80(4.90-9.20) 7.70(5.55-11.80) 9.70(6.00-15.30) 0.105$ (Ref. $\leq 8.7)[34]$

Hepcidin $[\mathrm{ng} / \mathrm{mL}] \quad 11.7(7.6-19.3) \quad 1.9(1.7-2.0) \quad 24.3(10.2-51.8) \quad 15.4(4.1-28.9) \quad 17.7(4.5-18.9) \quad 28.5(17.8-36.4) \quad 0.102$ Iron $[\mu \mathrm{mol} / \mathrm{L}] \quad$ (Ref. $5.8 \quad 17.0(9.8-21.9) \quad 13.0(10.5-15.3) \quad 13.9(10.7-22.5) \quad 15.2(9.9-21.5) \quad 6.9(4.7-8.9) \quad 15.3(9.7-18.0) \quad 0.158$ $-34.5)$

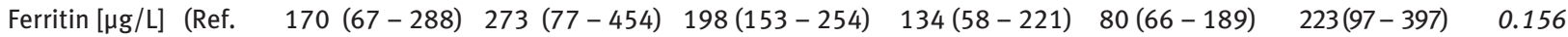
30 - 400)

Transferrin $[\mathrm{mg} / \mathrm{dL}] \quad 263(236-280) \quad 245(211-278) 297(258-321) \quad 272(245-303) 261(200-294) 233(205-264) 0.054$ (Ref. $200-360)$

TSAT [\%] (Ref. $16-\quad 27.0(16.0-31.0) 23.0(14.5-28.0) 20.5(13.5-34.0) \quad 21.0(15.0-33.0) 11.0(9.5-12.0) \quad 25.0(16.0-35.0) 0.136$ 45)

Haemoglobin $[\mathrm{g} / \mathrm{dL}] \quad 14.2(13.1-15.4) 14.9(14.2-16.4) 15.3(14.5-16.5) \quad 14.6(13.5-15.5) 14.1(13.5-14.9) 13.9(12.6-14.1) 0.053$ (Ref. 12.0 - 15.7*;

$13.0-17.7^{\#)}$

Ct-FGF23 $[\mathrm{RU} / \mathrm{mL}]$

$22.6(5.8-62.3) \quad 29.4(14.2-299.9) 39.0(32.8-72.0)$

$20.9(13.6-37.7) 97.9(16.3-139.9) 32.5(15.3-49.2) 0.334$

eGFR $[\mathrm{mL} / \mathrm{min} / 1.73 \mathrm{~m}$

(Ref. > 60)

$78.1(58.0-94.8) 68.6(42.8-77.8) 56.3(49.2-66.0)$

$78.1(67.6-93.1) 101.7(79.8-$ $61.1(48.4-71.2) 0.003$

NT-proBNP [ng/L] (Ref. 1185(358-3037) $1072(333-1942) \quad 1616(604-6710) \quad 1142(463-3197) 1964(617-3440) 2947(1191-$ 0 - 287)

4644)

\section{Haemodynamics}

LV-EF [\%]

RAP $[\mathrm{mmHg}]$ $39.0(25.1-45.0) 45.9(39.2-54.4) 46.7(38.0-56.8)$

$29.7(23.8-44.5) 26.5(23.0-28.0) 57.2(52.5-63.8)<0.001$

$\mathrm{CO}[\mathrm{L} / \mathrm{min}$

$\begin{array}{lll}9(7-12) & 8(5-10) & 10(7-14) \\ 3.7(2.8-4.7) & 3.0(2.5-5.4) & 4.9(2.8-6.6)\end{array}$

$9(6-11)$

$10(5-18)$

$10(8-14)$

0.771

Data from 149 patients are presented as median. *women; "men.

idiopath. $=$ idiopathic; hypert. $=$ hypertensive; inflame. $=$ inflammatory; Sig. $=$ significance; IQR $=$ interquartile range $\left(25^{\text {th }}\right.$ and $75^{\text {th }}$ percentile); $C M P$ = cardiomyopathy; Ref. = reference area; hypert. = hypertensive; inflam. = inflammatory; $A C E=$ angiotensin converting enzyme; $A R B=$ angiotensin receptor blocker; $M R A=$ mineralocorticoid receptor antagonist; $C R P=C$-reactive protein; TSAT = transferrin saturation; Ct-FGF23 = C-terminal fibroblast growth factor 23; eGFR = estimated glomerular filtration rate; NT-proBNP = N-terminal pro brain natriuretic peptide; $\mathrm{LV}-\mathrm{EF}=$ left ventricular ejection fraction; $\mathrm{RAP}=$ right atrial pressure; $\mathrm{CO}=$ cardiac output 

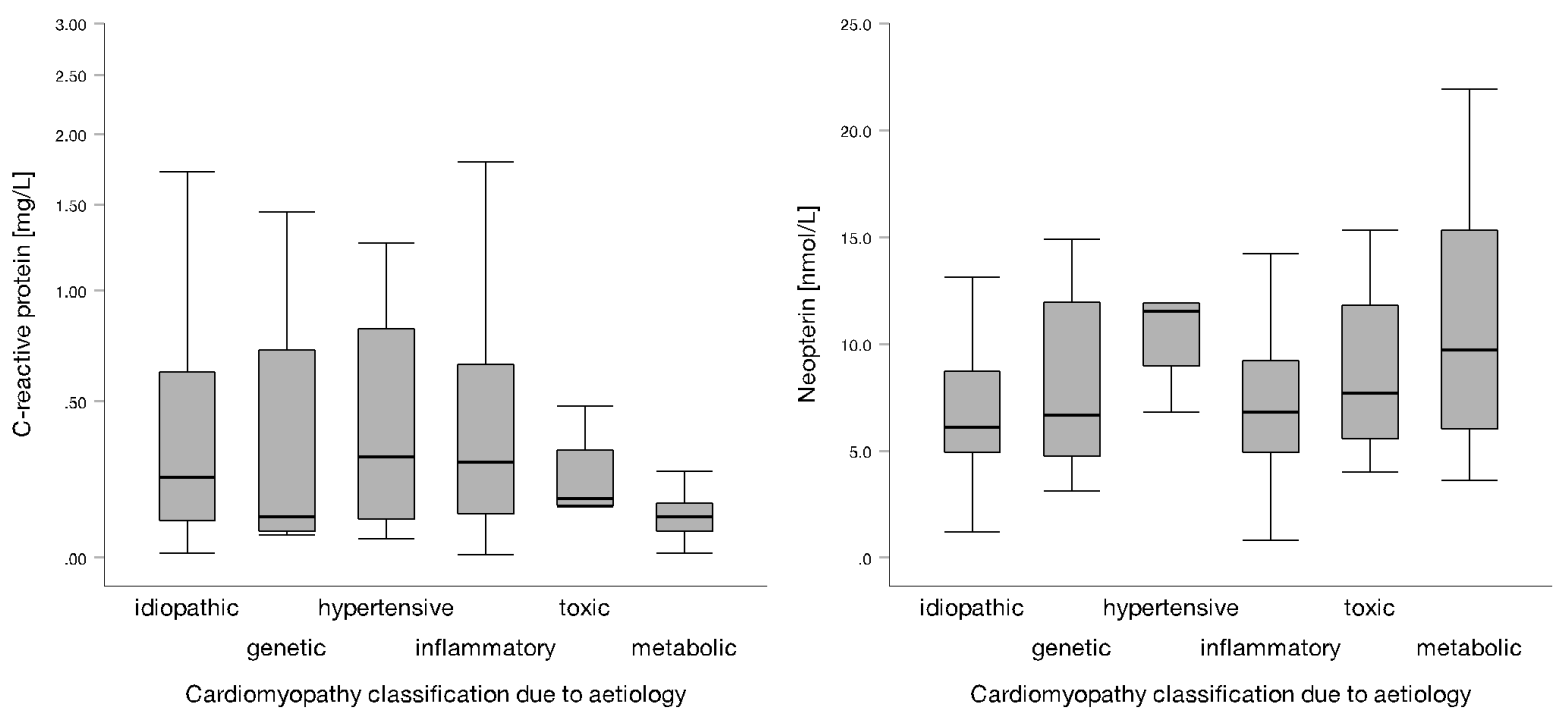

Figure 1: Boxplots of the two inflammatory markers, CRP and Neopterin within the specific CMP aetiologies: medians and ranges are shown. Idiopathic CMP $(n=31)$, genetic CMP $(n=8)$, inflammatory CMP $(n=85)$, toxic CMP $(n=4)$, metabolic CMP $(n=17)$.

\section{Results of endomyocardial biopsies: Myocarditis}

Endomyocardial biopsies (EMB) were analysed and patients were also classified due the occurrence of myocarditis (WHF/Dallas criteria). 61 patients (40.9\%) had no evidence of myocarditis, while 21 patients $(14.1 \%)$ showed an active myocarditis in the EMB and 67 patients ( $45.0 \%$ ) showed a chronic myocarditis in the EMB.

Patients with signs of myocarditis in the EMB had a significantly lower LV-EF compared to patients with no signs of myocarditis in the EMB (29.6\% [24.7 - 45.5] vs. $42.5 \%$ [34.0 - 55.4], $p=0.003)$. No differences were seen between patients with active and chronic myocarditis regarding LV-EF.

Interestingly, there were no differences of CRP and neopterin levels between patients with signs of myocarditis (CRP: $0.25 \mathrm{mg} / \mathrm{L}$ [0.11 - 0.67], neopterin: 6.90 $\mathrm{nmol} / \mathrm{L}$ [5.10 - 9.50]) compared to patients with no signs of myocarditis in the EMB (CRP: $0.16 \mathrm{mg} / \mathrm{L}$ [0.09 - 0.42], neopterin: $6.80 \mathrm{nmol} / \mathrm{L}$ [4.80 - 9.90]).

\section{Iron metabolism and cardiomyopathy aetiologies}

Patients with RCM had the lowest TSAT and iron levels as well as the highest transferrin levels. Haemoglobin levels were the highest in patients with DCM and the lowest in patients with undefined CMP (Table 1).
We also investigated parameters of iron metabolism in patients with inflammatory CMP subgroups: results are depicted in Figure 2 - significant differences between the groups are marked.

Moreover, we analysed for differences of iron metabolism parameters between patients within and without amyloid CMP: results are depicted in Figure 3 significant differences are marked.

No differences concerning iron metabolism parameters were detected between patients with (active or chronic or both) or without signs of myocarditis in the EMB. However, patients with signs of myocarditis tended to have lower ferritin concentrations compared to patients without signs of myocarditis in the EMB $(131 \mu \mathrm{g} / \mathrm{L}[57-$ $259]$ vs. $191 \mu \mathrm{g} / \mathrm{L}$ [89 - 291], $p=0.066$ ).

\section{Vitamin D metabolism and cardiomyopathy aetiologies}

The highest Ct-FGF23 concentrations were found in patients with RCM (Table 1). Patients with inflammatory CMP had lower Ct-FGF23 concentrations (20.9 RU/mL [13.6 - 37.7] vs. 32.5 RU/mL [14.8 - 58.3], $p=0.136$ ). Other vitamin D metabolism parameters showed no differences between the CMP aetiologies. In addition, there were no differences of vitamin $\mathrm{D}$ metabolism parameters between patients with or without sings of myocarditis in the EMB (active, chronic and both). 

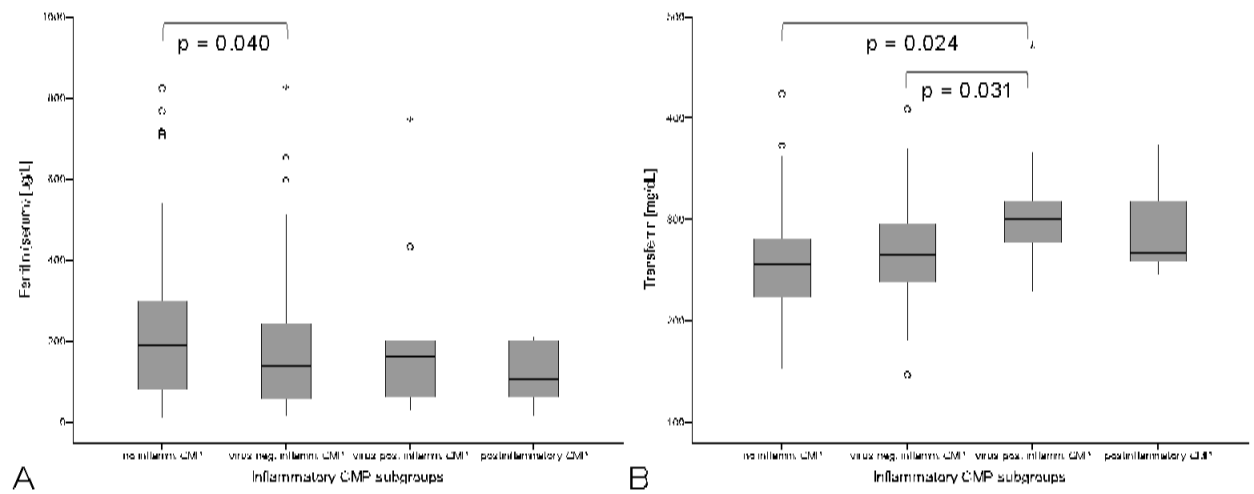

Figure 2: Boxplots of ferritin and transferrin levels in the different inflammatory CMP subgroups: Ferritin levels were significantly lower (134 $\mu \mathrm{g} / \mathrm{L}[58-221]$ vs. $188 \mu \mathrm{g} / \mathrm{L}[80-297], p=0.026$, A) and transferrin levels significantly higher $(272 \mathrm{mg} / \mathrm{dL}[245-303] \mathrm{vs} .257 \mathrm{mg} / \mathrm{dL}$ [223 281], $p=0.024, \mathrm{~B})$ in patients with inflammatory CMP compared to those with no inflammatory CMP. Other iron metabolism parameters did not differ.
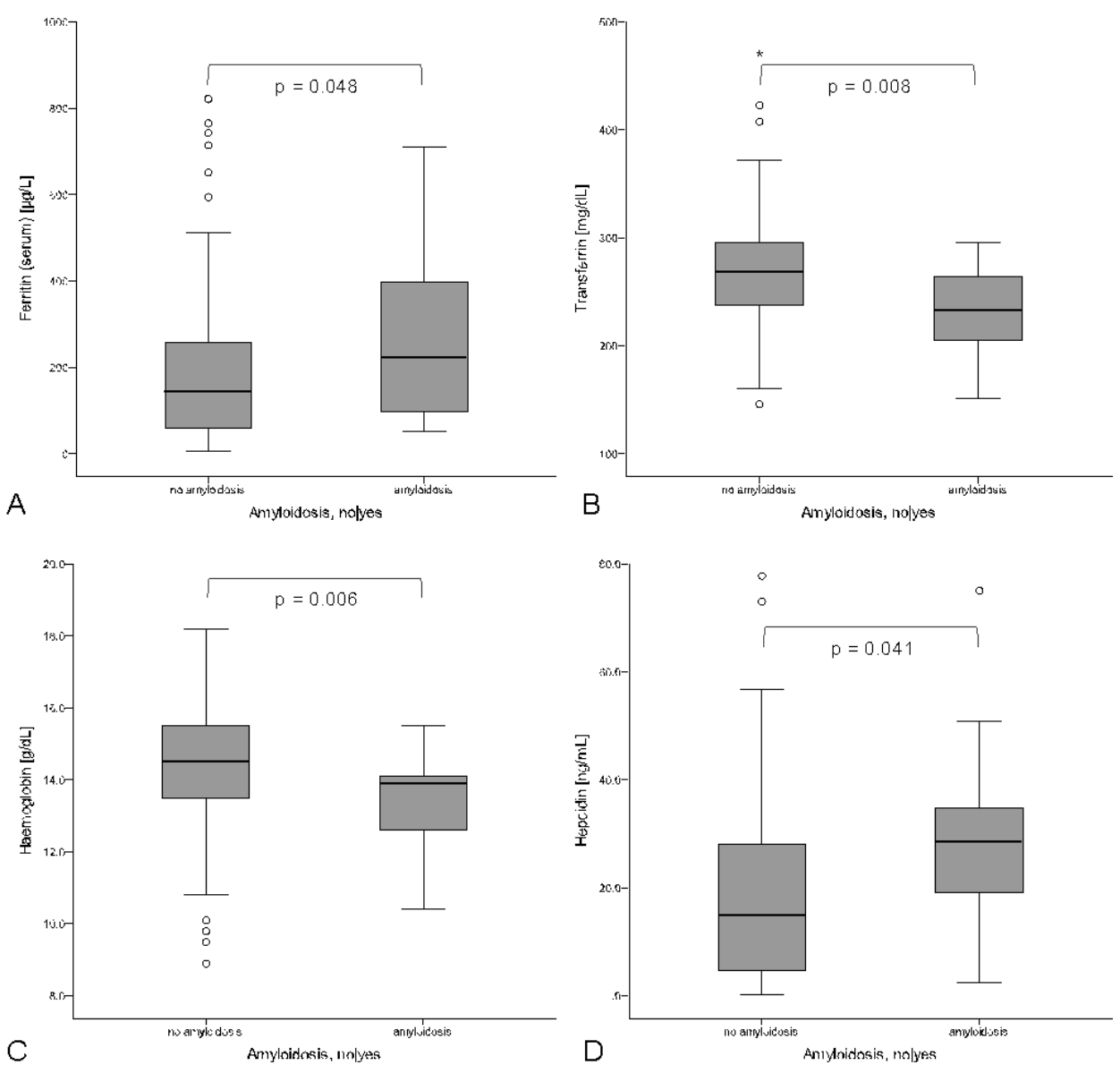

Figure 3: Boxplots of iron metabolism parameters in patients with and without amyloid CMP: Patients with amyloid CMP showed significantly higher ferritin concentrations $(223 \mu \mathrm{g} / \mathrm{L}[97-397] \mathrm{vs} .145 \mu \mathrm{g} / \mathrm{L}[59-259], p=0.048, \mathrm{~A})$ and significantly lower transferrin concentrations (233 mg/dL [205 - 264] vs. $268 \mathrm{mg} / \mathrm{dL}$ [239 - 296], $p=0.008$, B) compared to patients with no amyloid CMP. Additionally, haemoglobin concentrations were significantly lower (13.9 g/dL [12.6 - 14.1] vs. $14.5 \mathrm{~g} / \mathrm{dL}[13.5-15.5], p=0.006, \mathrm{C})$ and hepcidin concentrations significantly higher $(28.5 \mathrm{ng} / \mathrm{mL}[17.8-36.4] \mathrm{vs} .14 .7 \mathrm{ng} / \mathrm{mL}[4.8-28.1], p=0.041$, D) in patients with amyloid CMP compared to patients with no amyloid CMP. 

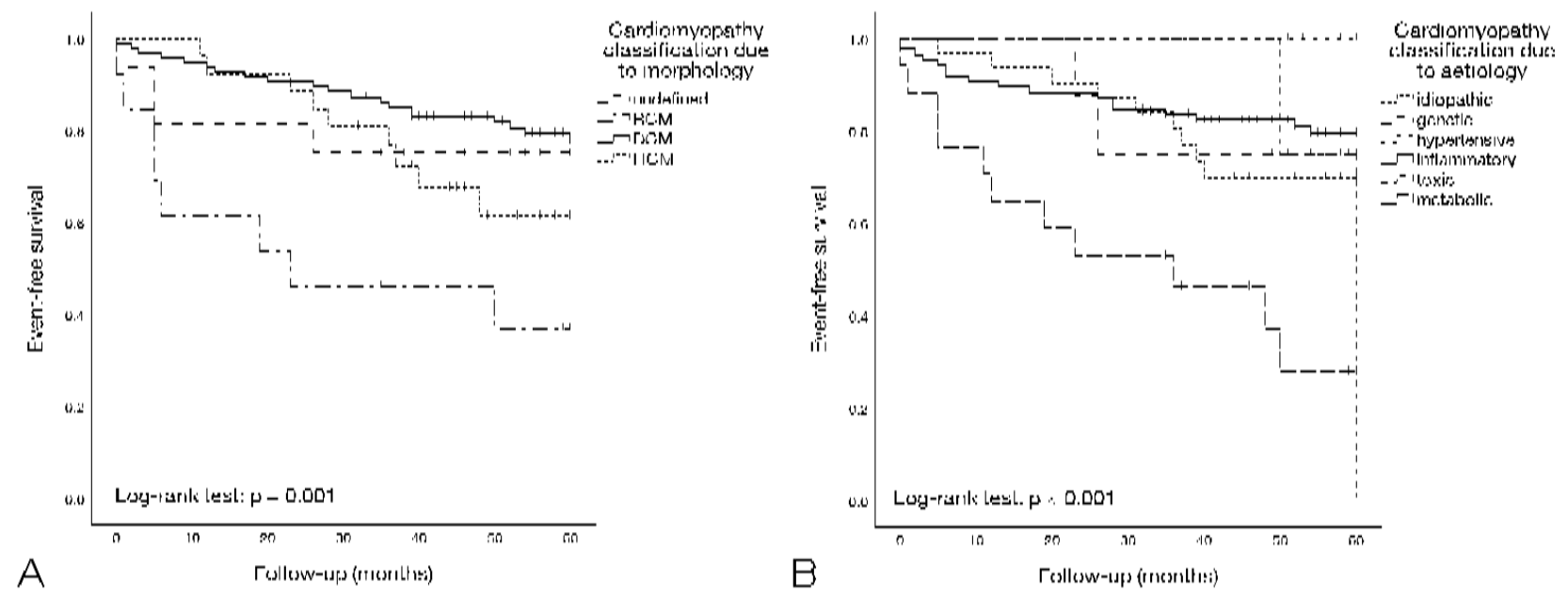

Figure 4: Kaplan-Meier survival analysis according to morphologic CMP classification (A) and CMP aetiologies (B). RCM ( $n=13)$, DCM $(n=94), \operatorname{HCM}(n=26)$, undefined $(n=16)$; idiopathic CMP $(n=31)$, genetic CMP $(n=8)$, hypertensive CMP $(n=4)$, inflammatory CMP $(n=85)$, toxic CMP $(n=4)$, metabolic CMP $(n=17)$.

\section{Outcome analysis and cardiomyopathy aetiologies}

Patients with RCM had a three-fold higher event-rate (63.1 $\%)$ compared to patients with DCM (22.3\%). The event-rate of patients with HCM was also nearly twice as high (38.7 $\%)$ compared to patients with DCM ( $p=0.001$, Figure 4A).

Patients with amyloidosis showed the highest event rate after 5 years $(72.2 \%$ vs. $20.6 \%$ in patients with inflammatory CMP and $30.1 \%$ in patients with idiopathic CMP all $p<0.001$, Figure 4B).

\section{Discussion}

Amyloid CMP represents as RCM with a rapidly progressive and fatal pathogenesis. This is confirmed by our study, since patients with amyloid CMP, which appears as RCM, as well as patients with RCM had the highest event rate after 5 years. Recent studies demonstrated, that amyloidosis triggers inflammatory reactions [35] and is associated with increased systemic and cardiac oxidative stress [3638]. T-helper cell type $1\left(\mathrm{TH}_{1}\right)$ immune activation results in the activation of macrophages, which produce neopterin concomitantly to reactive oxygen species (ROS) [39-41]. In our study, neopterin levels were found to be significantly higher in patients with amyloid CMP compared to patients with other CMP aetiologies. Moreover, significantly higher ferritin and hepcidin levels, which are both conditions that are seen in patients with a $\mathrm{TH}_{1}$ immune activation [27], were found in patients with amyloid CMP compared to patients with other CMP aetiologies. This indicates that $\mathrm{TH}_{1}$ immune activation with recruitment of activated macrophages into the myocardium as a consequence of deposited amyloid proteins might be a more important pathophysiological mechanism compared to other CMP aetiologies and goes along with changes of the iron storage capacity. Nevertheless, patients with amyloid CMP do not show decreased serum iron levels or a low TSAT as one would expect in patients with fully developed anaemia of chronic disease (ACD) [27]. Interestingly, patients with amyloid CMP also had the lowest CRP concentrations - which is in line with the notion that elevated CRP is associated with $\mathrm{TH}_{2}$ rather than $\mathrm{TH}_{1}$ immune response. Patients with amyloid CMP were also the oldest patients with a median age of approximately 70 years, which is in accordance with actual literature [25]. Further studies with larger patient cohorts will be needed to investigate the impact of inflammation and changes of iron metabolism on the pathophysiology of amyloid CMP.

Contrary to patients with amyloid CMP, patients with inflammatory CMP had higher CRP levels compared to patients with no inflammatory CMP, while neopterin levels did not differ. Interestingly, there were no differences of median CRP and neopterin levels between patients with virus positive and virus negative inflammatory CMP as well as between patients with and without signs of myocarditis in the EMB (both acute and/or chronic). This is in contrast to previous studies, which described higher neopterin levels in patients with inflammatory CMP, especially in patients with active myocarditis [42-44]. Since immune activation goes along with increased ferritin levels 
(ferritin is inter alia an acute phase protein), significantly higher ferritin levels in patients with inflammatory CMP might be expected [45]. Still, in our study patients with other CMP aetiologies had higher ferritin levels than patients with inflammatory CMP. Inflammation is known to be a leading cause of iron metabolism disturbances; however, other CMP aetiologies may trigger additional pathophysiological mechanisms. Nevertheless, when comparing patients with virus negative and virus positive inflammatory CMP, the latter showed significantly higher ferritin levels. Interestingly, there were no differences concerning iron metabolism parameters between patients with (active or chronic or both) or without signs of myocarditis in the EMB.

Ct-FGF23 levels were also lower in patients with virus positive inflammatory CMP compared to patients with virus negative inflammatory CMP and with no inflammatory CMP. Further longitudinal studies will be needed to better characterize the role of inflammation and immune-mediated disturbances of iron and vitamin D metabolism in patients with different kinds of CMP.

\section{Strengths and limitations}

Because of the low number of patients within some CMP aetiology subgroups and the fact that neopterin, Ct-FGF23 and iron metabolism parameters were not available of all patients initially included in the study, the findings of a small patient cohort do not allow unrestricted generalisation for all cardiomyopathy patients. The small number of patients within some CMP aetiology subgroups did not allow us to analyse for gender-differences in an appropriate way. As we also did not have data of all patients' co-morbidities and potential risk factors such as smoking or alcohol consumption studies including those factors would also be of interest.

\section{Conclusion}

This study indicates that the extent of inflammation varies in patients with CMP of different aetiologies. Furthermore, we could find changes of iron and vitamin D metabolism in CMP, which are worth being investigated in more detail in larger patient cohorts.

Funding: This research did not receive any specific grant from funding agencies in the public, commercial, or notfor-profit sectors.
Conflict of Interest: Dietmar Fuchs is Pteridines' Editorin-Chief; Günter Weiss and Katharina Kurz are Pteridines' Editorial Board members.

\section{References}

1. Richardson P, McKenna W, Bristow M, Maisch B, Mautner B, O'Connell J, et al. Report of the 1995 World Health Organization/International Society and Federation of Cardiology Task Force on the Definition and Classification of cardiomyopathies. Circulation. 1996 Mar;93(5):841-2.

2. Elliott P, Andersson B, Arbustini E, Bilinska Z, Cecchi F, Charron $P$, et al. Classification of the cardiomyopathies: a position statement from the European Society Of Cardiology Working Group on Myocardial and Pericardial Diseases. Eur Heart J. 2008 Jan;29(2):270-6.

3. Anker SD, Comin Colet J, Filippatos G, Willenheimer R, Dickstein K, Drexler H, et al.; FAIR-HF Trial Investigators. Ferric carboxymaltose in patients with heart failure and iron deficiency. N Engl J Med. 2009 Dec;361(25):2436-48.

4. Luk A, Ahn E, Soor GS, Butany J. Dilated cardiomyopathy: a review. J Clin Pathol. 2009 Mar;62(3):219-25.

5. Maron BJ, Gardin JM, Flack JM, Gidding SS, Kurosaki TT, Bild DE. Prevalence of hypertrophic cardiomyopathy in a general population of young adults. Echocardiographic analysis of 4111 subjects in the CARDIA Study. Coronary Artery Risk Development in (Young) Adults. Circulation. 1995 Aug;92(4):785-9.

6. Maron BJ, Maron MS. Hypertrophic cardiomyopathy. Lancet. 2013 Jan;381(9862):242-55.

7. Muchtar E, Blauwet LA, Gertz MA. Restrictive Cardiomyopathy: Genetics, Pathogenesis, Clinical Manifestations, Diagnosis, and Therapy. Circ Res. 2017 Sep;121(7):819-37.

8. Corrado D, Link MS, Calkins H. Arrhythmogenic Right Ventricular Cardiomyopathy. N Engl J Med. 2017 Apr;376(15):1489-90.

9. Maron BJ, Towbin JA, Thiene G, Antzelevitch C, Corrado D, Arnett D, et al.; American Heart Association; Council on Clinical Cardiology, Heart Failure and Transplantation Committee; Quality of Care and Outcomes Research and Functional Genomics and Translational Biology Interdisciplinary Working Groups; Council on Epidemiology and Prevention. Contemporary definitions and classification of the cardiomyopathies: an American Heart Association Scientific Statement from the Council on Clinical Cardiology, Heart Failure and Transplantation Committee; Quality of Care and Outcomes Research and Functional Genomics and Translational Biology Interdisciplinary Working Groups; and Council on Epidemiology and Prevention. Circulation. 2006 Apr;113(14):1807-16.

10. Sagar S, Liu PP, Cooper LT Jr. Myocarditis. Lancet. 2012 Feb;379(9817):738-47.

11. Cooper LT Jr. Myocarditis. N Engl J Med. 2009 Apr;360(15):1526-38.

12. Pollack A, Kontorovich AR, Fuster V, Dec GW. Viral myocarditisdiagnosis, treatment options, and current controversies. Nat Rev Cardiol. 2015 Nov;12(11):670-80. 
13. Haddad F, Berry G, Doyle RL, Martineau P, Leung TK, Racine N. Active bacterial myocarditis: a case report and review of the literature. J Heart Lung Transplant. 2007 Jul;26(7):745-9.

14. Marcon G, Callegari E, Scevola M, Bettin M, Pozzati G, Zolli $M$, et al. [Acute rickettsial myocarditis. Description of a clinical case and review of the literature]. G Ital Cardiol. 1988 Jan;18(1):72-5.

15. Russack V. Aspergillus terreus myocarditis: report of a case and review of the literature. Am J Cardiovasc Pathol. 1990;3(3):2759.

16. Cunha-Neto E, Chevillard C. Chagas disease cardiomyopathy: immunopathology and genetics. Mediators Inflamm. 2014;2014:683230.

17. Kirchhoff LV, Weiss LM, Wittner M, Tanowitz HB. Parasitic diseases of the heart. Front Biosci. 2004 Jan;9(1-3):706-23.

18. Spodick DH. Eosinophilic myocarditis. Mayo Clin Proc. 1997 Oct;72(10):996.

19. La Grenade L, Graham D, Trontell A. Myocarditis and cardiomyopathy associated with clozapine use in the United States. N Engl J Med. 2001 Jul;345(3):224-5.

20. Bourgeois GP, Cafardi JA, Groysman V, Hughey LC. A review of DRESS-associated myocarditis. J Am Acad Dermatol. 2012 Jun;66(6):e229-36.

21. Jentzen JM. Cocaine-induced myocarditis. Am Heart J. 1989 Jun;117(6):1398-9.

22. Ansari A, Maron BJ, Berntson DG. Drug-induced toxic myocarditis. Tex Heart Inst J. 2003;30(1):76-9.

23. Dionne A, Dahdah N. Myocarditis and Kawasaki disease. Int J Rheum Dis. 2018 Jan;21(1):45-9.

24. Qiao L, Gao D. A case report and literature review of ChurgStrauss syndrome presenting with myocarditis. Medicine (Baltimore). 2016 Dec;95(51):e5080.

25. Patel KS, Hawkins PN. Cardiac amyloidosis: where are we today? J Intern Med. 2015 Aug;278(2):126-44.

26. Frantz S, Falcao-Pires I, Balligand JL, Bauersachs J, Brutsaert $D$, Ciccarelli $M$, et al. The innate immune system in chronic cardiomyopathy: a European Society of Cardiology (ESC) scientific statement from the Working Group on Myocardial Function of the ESC. Eur J Heart Fail. 2018 Mar;20(3):445-59.

27. Weiss G, Goodnough LT. Anemia of chronic disease. N Engl J Med. 2005 Mar;352(10):1011-23.

28. Zhang H, Zhabyeyev P, Wang S, Oudit GY. Role of iron metabolism in heart failure: from iron deficiency to iron overload. Biochim Biophys Acta Mol Basis Dis. 2019 Jul;1865(7):1925-37.

29. Jankowska EA, Rozentryt P, Witkowska A, Nowak J, Hartmann O, Ponikowska B, et al. Iron deficiency predicts impaired exercise capacity in patients with systolic chronic heart failure. J Card Fail. 2011 Nov;17(11):899-906.

30. Jankowska EA, Rozentryt P, Witkowska A, Nowak J, Hartmann 0 , Ponikowska B, et al. Iron deficiency: an ominous sign in patients with systolic chronic heart failure. Eur Heart J. 2010 Aug;31(15):1872-80.

31. Gujja P, Rosing DR, Tripodi DJ, Shizukuda Y. Iron overload cardiomyopathy: better understanding of an increasing disorder. J Am Coll Cardiol. 2010 Sep;56(13):1001-12.

32. Vervloet $M$. Renal and extrarenal effects of fibroblast growth factor 23. Nat Rev Nephrol. 2019 Feb;15(2):109-20.

33. Czaya B, Faul C. The Role of Fibroblast Growth Factor 23 in Inflammation and Anemia. Int J Mol Sci. 2019 Aug;20(17):4195.
34. Werner ER, Bichler A, Daxenbichler G, Fuchs D, Fuith LC, Hausen $A$, et al. Determination of neopterin in serum and urine. Clin Chem. 1987 Jan;33(1):62-6.

35. Wang YH, Zhang YG. Amyloid and immune homeostasis. Immunobiology. 2018 Mar;223(3):288-93.

36. Migrino RQ, Hari P, Gutterman DD, Bright M, Truran S, Schlundt $B$, et al. Systemic and microvascular oxidative stress induced by light chain amyloidosis. Int J Cardiol. 2010 Nov;145(1):67-8.

37. Brenner DA, Jain M, Pimentel DR, Wang B, Connors LH, Skinner $M$, et al. Human amyloidogenic light chains directly impair cardiomyocyte function through an increase in cellular oxidant stress. Circ Res. 2004 Apr;94(8):1008-10.

38. Liao R, Jain M, Teller P, Connors LH, Ngoy S, Skinner M, et al. Infusion of light chains from patients with cardiac amyloidosis causes diastolic dysfunction in isolated mouse hearts. Circulation. 2001 Oct;104(14):1594-7.

39. Eisenhut M. Neopterin in Diagnosis and Monitoring of Infectious Diseases. J Biomark. 2013;2013:196432.

40. Wirleitner B, Reider D, Ebner S, Böck G, Widner B, Jaeger M, et al. Monocyte-derived dendritic cells release neopterin. J Leukoc Biol. 2002 Dec;72(6):1148-53.

41. Gostner JM, Becker K, Fuchs D, Sucher R. Redox regulation of the immune response. Redox Rep. 2013;18(3):88-94.

42. Samsonov M, Nassonov E, Kostin S, Samko A, Alexandrova L, Masenko V, et al. Serum neopterin-possible immunological marker of myocardial inflammation in patients with dilated heart muscle disease. Eur Heart J. 1991 Aug;12 Suppl D:151-3.

43. Samsonov M, Fuchs D, Reibnegger G, Belenkov JN, Nassonov EL, Wachter H. Patterns of serological markers for cellular immune activation in patients with dilated cardiomyopathy and chronic myocarditis. Clin Chem. 1992 May;38(5):678-80.

44. Wojciechowska C, Wodniecki J, Wojnicz R, Romuk E, Jacheć W, Tomasik A, et al. Neopterin and beta-2 microglobulin relations to immunity and inflammatory status in nonischemic dilated cardiomyopathy patients. Mediators Inflamm. 2014;2014:585067.

45. Andrews NC. Disorders of iron metabolism. N Engl J Med. 1999 Dec;341(26):1986- 95. 